\title{
Contribution of nanoclays to the barrier properties of a model proton exchange membrane for fuel cell application
}

\author{
Jean-Michel Thomassin $^{(1)}$, Christophe Pagnoulle ${ }^{(1)}$, Giuseppe Caldarella ${ }^{(2)}$, Albert Germain ${ }^{(2)}$, Robert Jérôme ${ }^{(1)}$ \\ (1) Center for Education and Research on Macromolecules (CERM), University of Liège, Sart-Tilman B6, \\ B-4000 Liège, Belgium

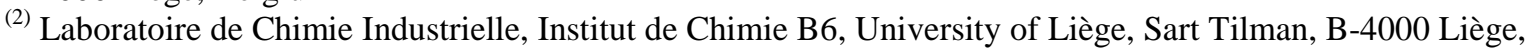 \\ Belgium
}

\begin{abstract}
Direct methanol fuel cells (DMFCs) that use a proton exchange membrane (PEM) as electrolyte, is a promising alternative source of energy for the future. However, methanol crossover from the anodic side to the cathodic one is a major problem in DMFC. Proper dispersion of layered silicates within the fuel cell membrane has been proposed as a strategy for improving the barrier properties of the membrane. The validity of this approach has been tested in case of a model membrane consisting of phosphotungstic acid doped poly(vinyl alcohol). A solvent casting technique has been used, which allows the nanofiller to be delaminated by an ultrasonic pretreatment, as confirmed by TEM and XRD analysis. The layered silicates have a favourable impact on the methanol permeability, whose the decrease overcompensates some loss in ionic conductivity.
\end{abstract}

Keywords: Fuel cell; Membrane; Montmorillonite; Poly(vinyl alcohol)

\section{Introduction}

At the time being, fuel cells have the potential at least to complement and possibly to substitute batteries in portable applications, because of high electrical efficiency, adjustable power and capacity, long lifetime and valuable ecological balance. Substitution of liquid methanol for traditional hydrogen fuel offers several advantages, including easier storage and more straightforward implementation because humidification and thermal management, fuel vaporiser or reformer are no longer needed. However, the direct methanol fuel cell (DMFC) has the disadvantage of a much slower oxidation kinetics of methanol compared to hydrogen and, above all, of the methanol permeation through the polymer membrane, which is commonly referred to as methanol crossover [1]. Indeed, a high methanol permeability is the common drawback of all the membranes used nowadays in DMFCs, i.e. perfluorosulfonated ionomers (PFSI), such as Nafion ${ }^{\circledR}$, sulfonated polyaromatics, including polysulfone (PSUs) [2,3], polyetheretherketone (SPEEK) [4,5] and polyphenylene oxide (SPPO) [6], and polybenzimidazole $[7,8]$. The main strategy used until now toovercome this problem consists in dispersing inorganic fillers, such as silica [9], heteropolyacid [10,11], and zirconium phosphate [12] within the polymer. Nevertheless, the improvement in methanol permeability remains marginal, more likely because of the unappropriate size and shape of the filler.

This work aims at testing a strategy based on the dispersion of a nanoscaled multi-layered alumino-silicate (montmorillonite). The high (length to width) aspect ratio of this nanofiller is expected to decrease significantly the methanol cross-over as result of a much longer diffusion pathway. The success of this strategy relies however on the actual dispersion state of the multi-layered silicate, which may lie between three typical situations schematized in Fig. 1.

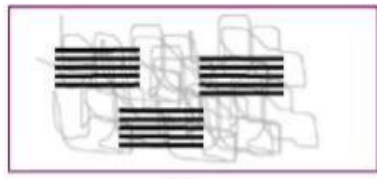

(a)

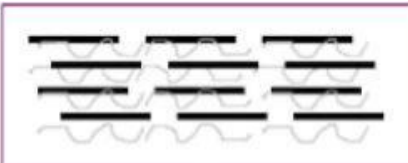

(b)

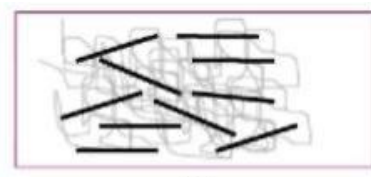

(c)

Fig. 1. The typical dispersion states of a nanoclay within a polymer: (a) no chain penetration, (b) chain intercalation, and (c) clay exfoliation. 
Either the silicate layers are not penetrated by polymer chains and a microcomposite is formed (Fig. 1a), or chains are intercalated between the silicate sheets (Fig. 1b) or the silicate layers are completely exfoliated and uniformly dispersed within the polymer so resulting in a nanocomposite (Fig. 1c). For the barrier properties of the polymer matrix to be improved, the exfoliation of the multi-layered silicate is a prerequisite for maximizing the tortuosity factor $(\mathrm{T})$, defined as the ratio of the actual distance $\left(d^{\prime}\right)$ that a penetrant must travel to the shortest distance $(d)$ that it would have traveled in absence of the filler (Fig. 2) [13]. This factor is expressed by Eq. (1):

$$
\tau=\frac{d^{\prime}}{d}=\mathbf{I}+\frac{L}{2 W} \Phi_{\mathrm{s}}
$$

where $L, W$ and $\Phi$ are the length, the thickness, and the volume fraction of the silicate layers, respectively. $L / W$ is the anisotropy factor.

In a previous study, we have shown that although nanoclays resist complete exfoliation within Nafion ${ }^{\circledR}[14,15]$, the methanol permeability of this polymer is decreased by the multi-layered alumino-silicate. This preliminary observation is a strong incentive to model a situation in which the alumino-silicate would be completely delaminated within a polymer usable as a fuel cell membrane. Poly(vinyl alcohol) (PVOH) is a good candidate for this purpose, because silicate layers are known for good dispersion in this polymer [16,17]. Moreover, doping of PVOH by an inorganic acid, such as hypophosphoric acid [18] and phosphotungstic acid [19] is an easy way to increase the ionic conductivity, which makes it a potential candidate as a fuel cell membrane [20], at least at not exceedingly high temperature, at which the polymer would be soluble in water.

Because the proton transport throughout the membrane is facilitated by water, it is also favoured by methanol that has very similar physical properties as water. It is therefore a challenging task to decrease the methanol permeability without decreasing the ionic conductivity, which explains that the performances of a fuel cell membrane are better expressed by the balance between protonic conductivity $(C)$ and methanol permeability $(P)$, i.e. the $C / P$ ratio ( ) [21].

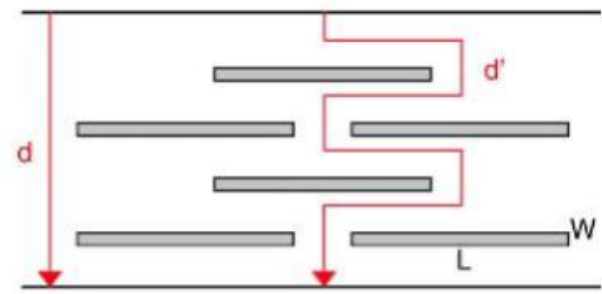

Fig. 2. Schematic view of the tortuosity factor.

\section{Experimental}

\subsection{Membrane preparation and characterization}

Poly(vinyl alcohol) (PVOH) (99\% hydrolyzed, average $\left.M_{\mathrm{W}}=124,000-186,000\right)$ and phosphotungstic acid (PWA) were purchased from Aldrich, and sodium montmorillonite (Cloisite $\mathrm{Na}^{+}$) was a gift from Southern Clay Products. Membranes were prepared by casting a dispersion of Cloisite $\mathrm{Na}^{+}$in an aqueous solution of PVOH on a glass plate. The Cloisite $\mathrm{Na}^{+}$was first suspended in water $(>1 \mathrm{wt} . \%)$ at room temperature under stirring for $1 \mathrm{~h}$ and sonicated for $30 \mathrm{~min}$. PVOH (5 wt.\%) was then added, and the mixture was heated at $90{ }^{\circ} \mathrm{C}$ under stirring until the polymer was dissolved. After $30 \mathrm{~min}$ of sonification, the film was cast in a closed oven at $40{ }^{\circ} \mathrm{C}$ for 2 days. The membrane was then immersed in a phosphotungstic acid solution in water (0.66 wt.\%) for different periods of time, washed with water and finally dried at $40{ }^{\circ} \mathrm{C}$ under reduced pressure. Absence of defects was checked by optical microscopy observations and confirmed by the reproducibility of the barrier properties measurements.

Thermogravimetric analysis (TGA) was performed with the Hi-Res TGA Q500 from TA Instruments, under a nitrogen flow $\left(60 \mathrm{~cm}^{3} / \mathrm{min}\right)$ from 25 to $600{ }^{\circ} \mathrm{C}$ at a heating rate of $20{ }^{\circ} \mathrm{C} / \mathrm{min}$.

Thin sections $(90 \mathrm{~nm})$ of membranes were prepared by ultramicrotomy (ULTRACUT E from REICHERTJUNG) at $-130{ }^{\circ} \mathrm{C}$ and observed by transmission electron microscopy (PHILIPS M100; accelerating voltage of $100 \mathrm{kV}$ ). Micrographs were analyzed by using the KS 100 (Kontron Imaging System) software.

Nanofiller dispersion was also analyzed by X-ray diffraction (XRD) with a Siemens D5000 diffractometer $(\mathrm{Cu}$ K $\alpha$ radiation). The XRD data were collected between $1.5^{\circ}$ and $15^{\circ}$ by step of $0.01^{\circ}$ with an X-ray generator at $\lambda$ $=0.15406 \mathrm{~nm}$. 


\subsection{Methanol permeability [22]}

Methanol permeability was measured with a two-compartment cell. One compartment $\left(V_{\mathrm{A}}=100 \mathrm{ml}\right)$ was filled with a mixture of methanol (16vol.\%) and 1-butanol $(0.2 \mathrm{vol} . \%)$ in deizoned water. The second compartment $\left(V_{\mathrm{B}}\right.$ $=100 \mathrm{ml})$ was filled with a 1-butanol $(0.2 \mathrm{vol} . \%)$ solution in deizoned water.

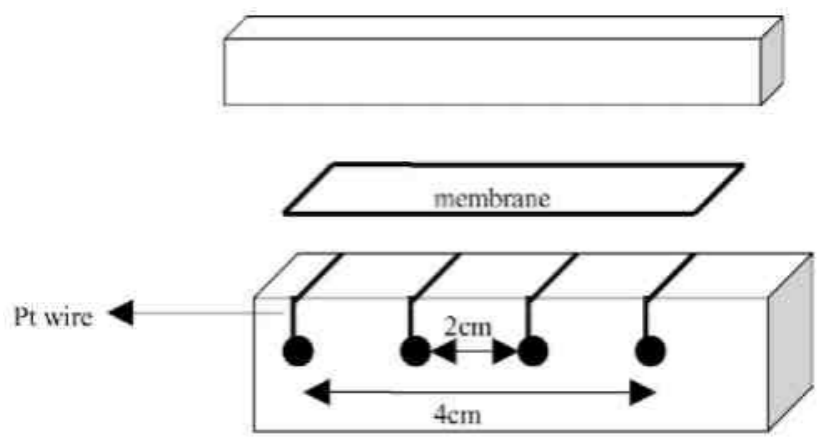

Fig. 3. Schematic view of the cell used for the measurement of the ionic conductivity.

The membrane (surface area $=28 \mathrm{~cm}^{2}$ ) was clamped between the two compartments and the methanol concentration in the receiving compartment was measured as a function of time by gas chromatography using 1 butanol as an internal reference. The time dependence of this concentration is given by Eq. (2):

$$
c_{\mathrm{B}}(t)=\frac{A}{V_{\mathrm{B}}} \frac{D K}{L} c_{\mathrm{A}}\left(t-t_{0}\right)
$$

where $c$ is the methanol concentration, $A$ and $L$ are the membrane area and thickness, respectively, $D$ and $K$ stand for the methanol diffusivity and the partition coefficient between the membrane and the adjacent solution, respectively. $D$ is supposed to be constant throughout the membrane and $K$ to be independent of concentration. The product $D K$ is the membrane permeability, which is calculated from the slope of the linear dependence of $\left(c_{\mathrm{B}} \times L\right)$ on time. For each membrane, the measurements were repeated at least three times and more if poor consistency was observed. The relative error was found smaller than $10 \%$.

\subsection{Ionic conductivity}

As shown in Fig. 3, the current was fed to the membrane $(4 \mathrm{~cm} \times 1 \mathrm{~cm})$ by two platinum (wires) electrodes $4 \mathrm{~cm}$ apart. Two platinum wires $(2 \mathrm{~cm}$ apart) allowed the potential drop along the membrane to be measured. The electrodes were screwed in a polycarbonate support riddled with holes that allowed the membrane to be equilibrated with the atmosphere.

Measurements were reported for $100 \%$ humidity, at room temperature. The membrane conductivity was thus measured in the longitudinal direction and calculated by Eq. (3):

$$
\sigma=\frac{l}{R S}
$$

where $\sigma$ is the ionic conductivity, $l$ the distance between the reference electrodes, $R$ the resistance of the membrane, and $S$ is the cross-sectional area.

Impedance was measured in the $1 \mathrm{~Hz}$ to $500 \mathrm{KHz}$ frequency range, with a potentiostat and a frequency-response analyser (Autolab model PGSTAT 30). For each membrane, the measurements were repeated at least three times and more if poor consistency was observed. The relative error was found smaller than $5 \%$.

\section{Results and discussion}

\subsection{Dispersion of cloisite $\mathrm{Na}^{+}$}

A typical TEM image of a poly(vinyl alcohol) membrane containing 5wt. $\%$ of Cloisite $\mathrm{Na}^{+}$is shown in Fig. $4 \mathrm{a}$. An extensive exfoliation of the silicate layers is observed as result of a high Cloisite $\mathrm{Na}^{+} / \mathrm{PVOH}$ affinity. An additional indirect evidence of this affinity can be found in the lack of voids at the interface after ultramicrotomy. Needless to say that a poor interfacial adhesion might be detrimental to the barrier properties of 
the membrane. Dispersion of Cloisite $\mathrm{Na}^{+}$is expectedly unaffected by doping with the heteropolyacid (Fig. 4b), which leaves the interface strong enough to resist ultramicrotomy.

TEM observations have been confirmed by XRD analysis, which gives information on the interlamellar distance of the silicate additive. Indeed the diffraction peak characteristic of the clay remains unchanged in case of dispersion without intercalation and exfoliation. A shift of the diffraction peak towards larger interlamellar distance is the signature of chain intercalation, whereas this peak is no longer observed in case of exfoliation.

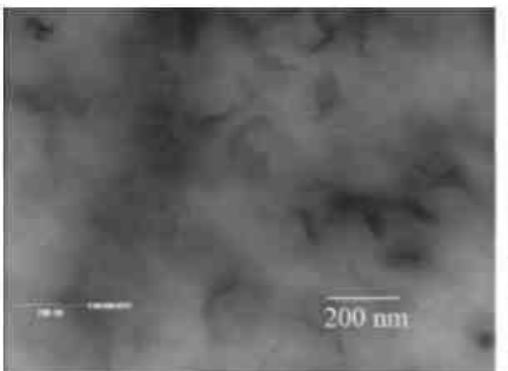

(a)

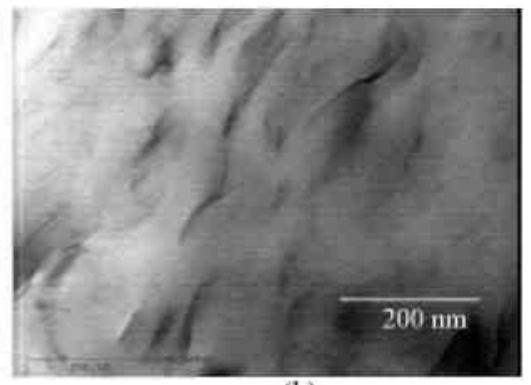

(b)

Fig. 4. TEM micrographs of PVOH membranes (a) filled with $10 \mathrm{wt} \%$ of Cloisite $\mathrm{Na}^{+}$; (b) filled with 5 wt.\% of Cloisite $\mathrm{Na}^{+}$and doped by $10 \mathrm{wt}$.\% of phosphotungstic acid.

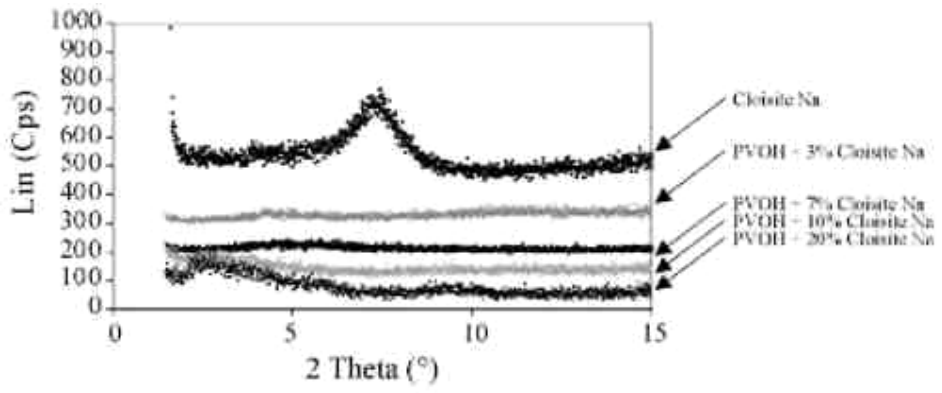

Fig. 5. X-ray diffraction patterns for PVOH membranes filled with different contents of Cloisite $\mathrm{Na}^{+}$.

Fig. 5 shows the X-ray diffraction patterns for Cloisite Na and for PVOH with different loadings of this nanoclay. Cloisite $\mathrm{Na}$ shows a diffraction peak at $7.5^{\circ}$, which corresponds to a basal space of $1.18 \mathrm{~nm}$. When $\mathrm{PVOH}$ is filled with less than $7 \%$ of Cloisite $\mathrm{Na}$, lack of diffraction peak indicates that the nanoclay is completely exfoliated. When more than $10 \%$ of filler is dispersed, a peak appears at $2.92^{\circ}$, from whicha basal space of $3.02 \mathrm{~nm}$ is calculated. Thus, when the content of Cloisite $\mathrm{Na}^{+}$is too high, chain intercalation dominates with possibly some degree of exfoliation.

\subsection{TGA studies}

Fig. 6 shows the TGA profiles for PVOH, phosphotungstic acid (PWA) and modified PVOH membranes. A twostep weight loss is reported for poly(vinyl alcohol), with a first step accounted for by the polymer dehydratation and formation of a "polyacetylene-like" structure. This phenomenon is delayed by the addition of $10 \mathrm{wt} . \%$ of Cloisite $\mathrm{Na}^{+}$, which may indicate that the outdiffusion of water is slown down by the nanoclay. In contrast, the inorganic acid causes the first weight loss step to be shifted to lower temperature. This observation is consistent with a catalytic effect of acid compounds on the dehydratation of poly(vinyl alcohol). The delayed-action of Cloisite $\mathrm{Na}^{+}$on the thermal decomposition is also observed for the doped membrane.

Fig. 5 shows that, after a loss of water at low temperature, the phosphotungstic acid does not degrade until 900 ${ }^{\circ} \mathrm{C}$. Therefore, higher residue content is systematically shown by the TGA curves in the $500-600{ }^{\circ} \mathrm{C}$ range whenever phosphotungstic acid is part of the membrane. This characteristic feature has been used to determine the PWA content of the nanocomposite membrane by TGA. 


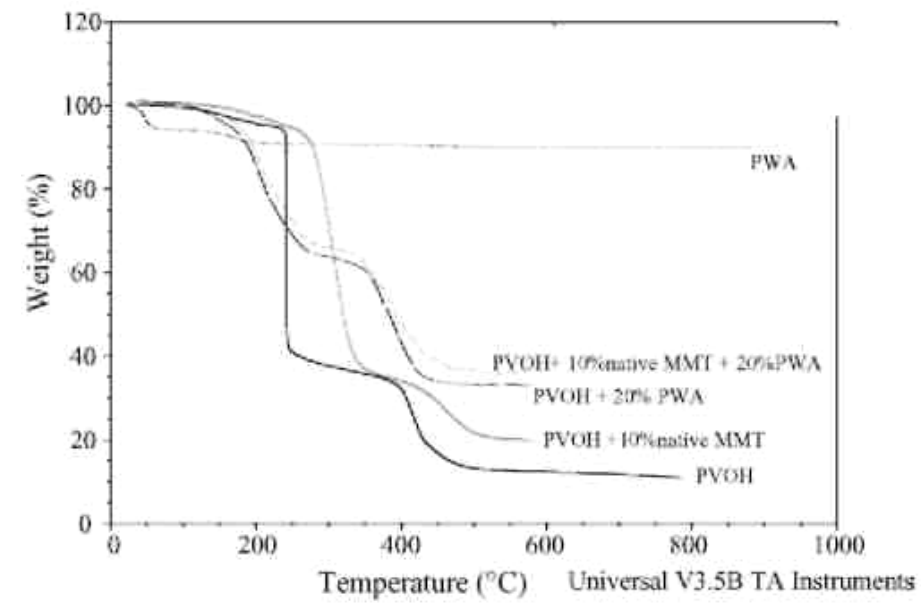

Fig. 6. TGA curves for PVOH, PWA and modified PVOH.

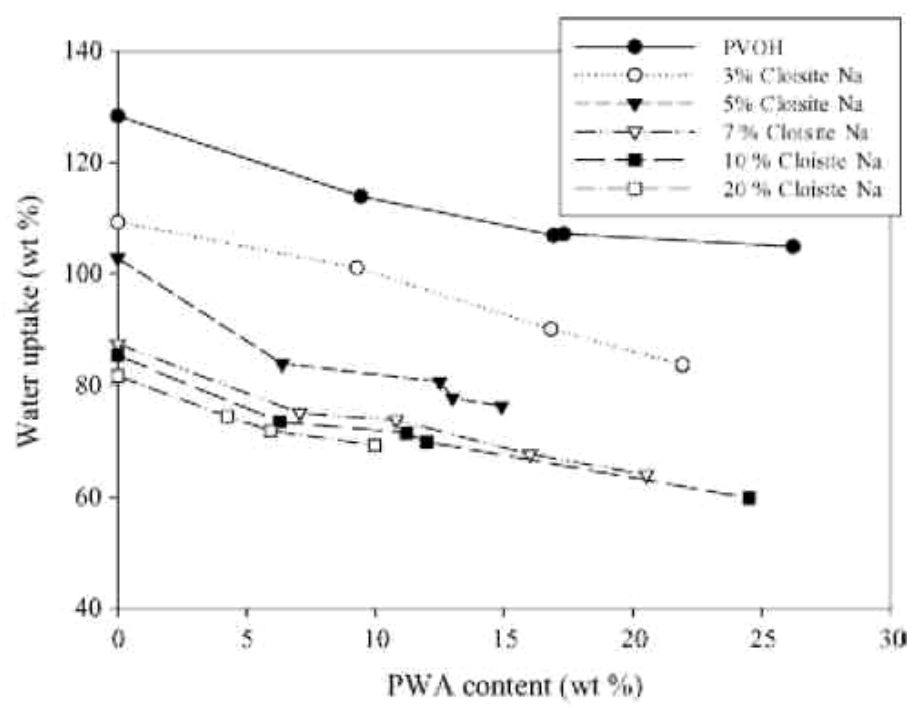

Fig. 7. Water uptake as a function of the PWA content for $\mathrm{PVOH}$ and $\mathrm{PVOH}$ loaded with Cloisite $\mathrm{Na}^{+}$.

\subsection{Water uptake}

The water uptake of the membrane is a key parameter in fuel cell technology. A too low water uptake systematically results in low ionic conductivity, whereas methanol permeability is enhanced and dimensional stability is lost for membranes with a high water uptake. The water uptake of the PVOH membranes depends on the PWA content as shown in Fig. 7. PVOH has a strong affinity for water to the point where the initial weight has increased more than two-fold upon immersion in water. Loading of PVOH by PWA decreases although not dramatically, the water absorption. Indeed, the water content of pure PVOH is $128 \%$ and it remains higher than $100 \%(105 \%)$ when more than $20 \mathrm{wt} . \%$ of PWA is added. When the polymer isfilled with Cloisite $\mathrm{Na}^{+}$, the water uptake decreases rapidly with the clay loading at least until $7 \mathrm{wt} . \%$ of nanoclay. At this loading, the water absorption of pure PVOH has fallen down to $87 \%$, which means a decrease of $32 \%$. Beyond 7 wt. $\%$ of nanoclay, the water uptake tends to level off, consistent with the observation that the exfoliation is no longer complete in this loading range. At a constant Cloisite $\mathrm{Na}^{+}$content, the addition of PWA has an effect comparable to that observed for pure $\mathrm{PVOH}$. 


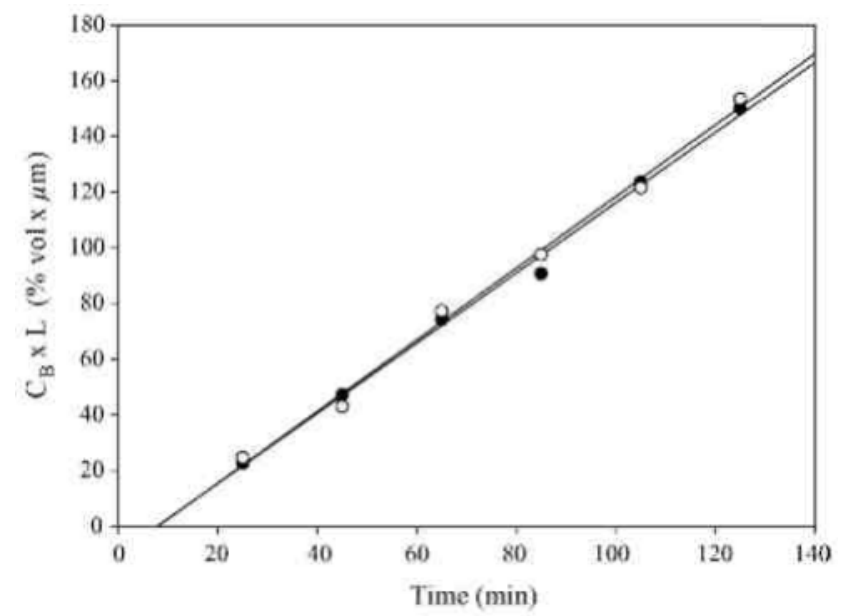

Fig. 8. Methanol permeability data for two independently prepared PVOH membranes.

\subsection{Methanol permeability}

The methanol permeability, thus the $D K$ factor, of the modified PVOH membranes has been determined from the slope of the time dependence of the $\left(C_{\mathrm{B}} \times L\right)$ product.

Fig. 8 shows the data for two independently prepared PVOH membranes and confirms the reproducibility of the method. The influence of both the PWA content and the nanoclay loading has been investigated. Fig. 9 shows that addition of the heteropolyacid to PVOH (loaded with Cloisite $\mathrm{Na}^{+}$or not) has a detrimental effect on the methanol permeability, particularly beyond $20 \mathrm{wt}$ \% PWA. This observation is surprising because the opposite effect would have been expected from the water uptake dependence on the PWA content (Fig. 7). Thus, although the water content is lower, PWA makes the methanol diffusion through PVOH easier, particularly when more than $20 \mathrm{wt} . \%$ PWA is added, which might be the percolation threshold for this additive. As a rule, dispersion of Cloisite $\mathrm{Na}^{+}$decreases strongly the methanol permeability of PVOH.

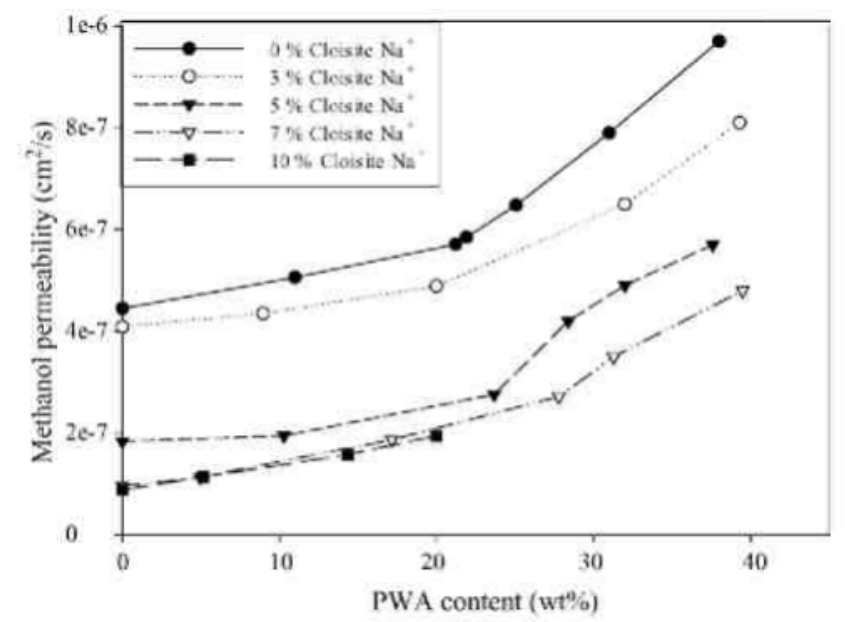

Fig. 9. Methanol permeability as a function of the PWA content for PVOH membranes loaded with Cloisite $\mathrm{Na}^{+}$. 


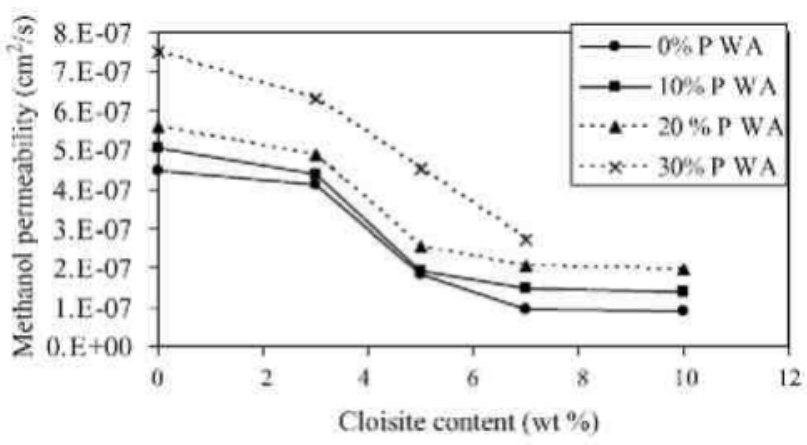

Fig. 10. Methanol permeability of $\mathrm{PVOH}$ as a function of the Cloisite $\mathrm{Na}^{+}$content at different PWA loadings.

This beneficial effect is highlighted by plotting the methanol permeability as a function of the Cloisite content (Fig. 10) for pure PVOH and for membranes doped with 10, 20, and $30 \mathrm{wt} \%$ of phosphotungstic acid.

Dispersion of Cloisite $\mathrm{Na}^{+}$until $7 \mathrm{wt} . \%$, thus as long as the nanoclay is exfoliated, triggers an important decrease of the methanol permeability. At this nanofiller content, the methanol permeability is decreased by approximatively $88 \%$ with respect to neat PVOH. Beyond $7 \mathrm{wt} \%$ Cloisite $\mathrm{Na}^{+}$, the methanol permeability levels off, more likely because the additional silicate layers do not contribute to increase the number of individual sheets but rather to form intercalated assemblies, which results in some increase in the $W / L$ factor as the volume fraction of the nanofiller is increased. Because $d^{\prime}$ (Fig. 2) does not change significantly, the effect of the $W / L$ ratio on the tortuosity factor is low and the methanol permeability of the membrane is not expected to change much with the Cloisite Na content (cfr Eq. (1)). It must be noted that the decrease in methanol permeability triggered by the nanoclay dispersion is comparatively much more important that the decrease in the water uptake. For instance, at $7 \mathrm{wt} . \%$ of Cloisite $\mathrm{Na}^{+}$, the water uptake is decreased by only $32 \%$ compared to $88 \%$ for the methanol permeability. This observation indicates that the improved barrier properties of PVOH result not only from a lower water content but also from an increase in the tortuosity factor.

\subsection{Ionic conductivity}

Fig. 11 shows the dependence of the ionic conductivity of PVOH membranes filled with Cloisite $\mathrm{Na}^{+}$on the PWA content. The proton conductivity of PVOH before doping is lower than $10-{ }^{4} \mathrm{~S} / \mathrm{cm}$. Expectedly, the inorganic acid improves substantially the transport of protons through $\mathrm{PVOH}$. The ionic conductivity is 0.008 $\mathrm{S} / \mathrm{cm}$ for a $40 \mathrm{wt}$ \% content of phosphotungstic acid, which amounts to approximatively $10 \%$ of the ionic conductivity of Nafion. Unfortunately, the PWA content cannot be increased further without sacrifying the mechanical stability of the PVOH membrane. Fig. 12 shows how the ionic conductivity of doped PVOH changes with the Cloisite $\mathrm{Na}^{+}$content. As a rule, the addition of Cloisite $\mathrm{Na}^{+}$results in a lower ionic conductivity. At low PWA content, this reduction is however very small, the ionic conductivity decreasing by only $15 \%$ upon the addition of $7 \%$ of Cloisite $\mathrm{Na}^{+}$. At high PWA content, this decrease in the ionic conductivity is approximatively two times more important $(28 \%)$ at the same nanoclay content.

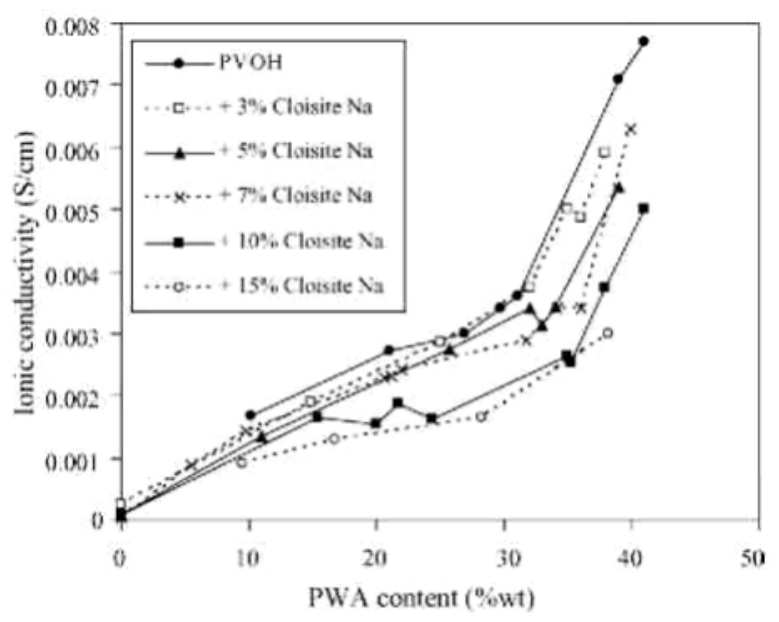

Fig. 11. Ionic conductivity as a function of the PWA content for PVOH membranes loaded by Cloisite $\mathrm{Na}^{+}$. 
This decrease which is very small compared to the decrease of methanol permeability (88\%) is more likely related to the reduced water uptake of PVOH composite membranes.

Addition of Cloisite $\mathrm{Na}^{+}$and PWA to PVOH has an important influence on both the methanol permeability and ionic conductivity. Cloisite $\mathrm{Na}^{+}$has a beneficial impact on the methanol permeability and a negative impact on the ionic conductivity, whereas the opposite effect is observed for the addition of phosphotungstic acid. In order to identify the ideal combination of these two additives, it is worth analyzing the experimental dependence of the ratio of the protonic conductivity to the methanol permeability $(C / P$ ratio) on both the Cloisite content (Fig. 13) and the PWA content (Fig. 14). Fig. 13 shows that the $C / P$ ratio remains constant at low Cloisite content. This ratio starts to increase when more than $3 \mathrm{wt} . \%$ of Cloisite $\mathrm{Na}^{+}$is added, which means that the decrease in the methanol permeability exceeds that one in the ionic conductivity. The $C / P$ ratio passes through a maximum at 7 wt. $\%$ of Cloisite $\mathrm{Na}^{+}$, which is the best content for improving the performances of the PVOH membranes.

Beyond $7 \mathrm{wt} . \%$ nanofiller, the $C / P$ ratio decreases because the methanol permeability does not change further in contrast to the ionic conductivity which goes on decreasing.

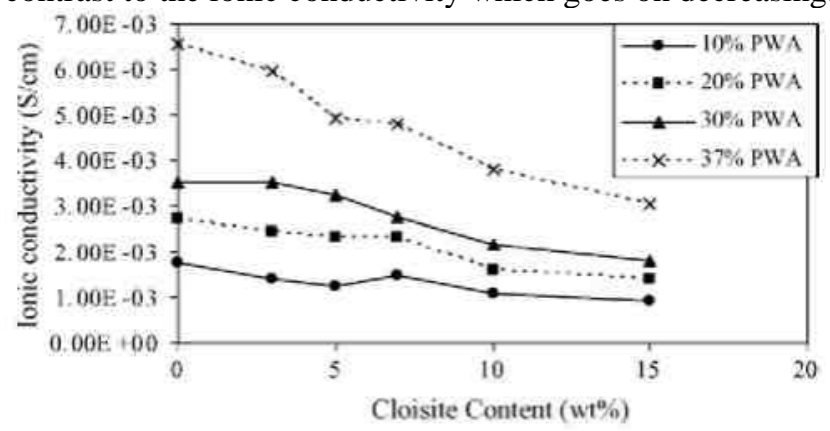

Fig. 12. Ionic conductivity as a function of the Cloisite $\mathrm{Na}^{+}$content of PVOH membranes.

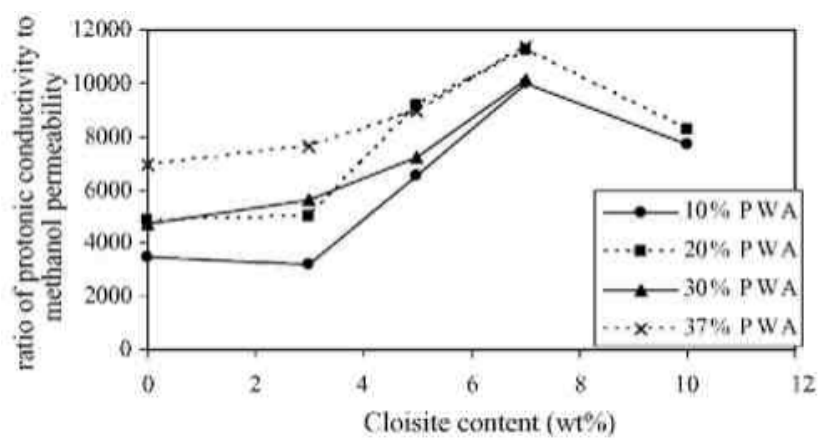

Fig. 13. C/P ratio as a function of the Cloisite $\mathrm{Na}^{+}$content for PVOH membranes doped by PWA.

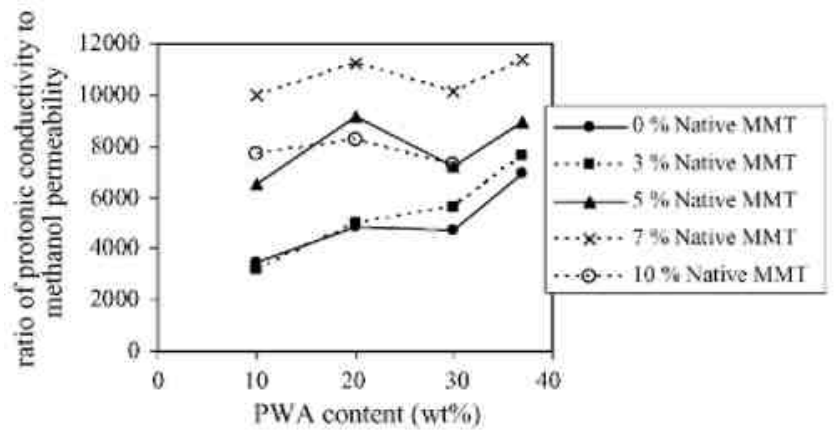

Fig. 14. C/P ratio as a function of the PWA content for PVOH membranes loaded by Cloisite $\mathrm{Na}^{+}$.

Dependence of the $C / P$ ratio on the PWA content is more complex. First, the ratio increases until $20 \mathrm{wt} . \%$ and then decreases duetothe increaseofmethanol permeability. Afterwards, the $C / P$ ratio increases again due to an increase of the ionic conductivity higher than the increase in methanol permeability. The more beneficial PWA contents would thus be 20 and 40 wt. $\%$. 


\section{Conclusion}

In this paper, we have studied the influence of the addition of nanoscaled multi-layered alumino-silicates (montmorillonite) on the barrier properties of a polymer usable as a membrane for fuel cell application. Because polymers commonly used as fuel cell membranes are not able to disperse the native nanoclay properly [14], poly(vinyl alcohol), in which the nanofiller is easily exfoliated, has been chosen as a model membrane. However, the ionic conductivity of this type of membraneisintrinsically low and doping by phosphotungstic acid is required. Measurement of the barrier properties of these membranes has shown that addition of only $7 \mathrm{wt} . \%$ of Cloisite $\mathrm{Na}$ is able to decrease the methanol permeability by $\sim 88 \%$ with respect to the neat polymer. However, addition of the nanoclay also decreases the ionic conductivity of the membrane, although this decrease $(28 \%$ with respect to the neat polymer) is largely lower compared to the methanol permeability. The ratio of protonic conductivity to methanol permeability $(C / P$ ratio) is thus largely increased by the addition of the layered silicate, that has clearly a beneficial impact on the performances of the fuel cell membrane. One should conclude that exfoliation of nanoclays within Nafion ${ }^{\circledR}$ and membranes of this type is a valuable target for improving the performances of direct methanol fuel cells.

\section{Acknowledgements}

CERM is grateful to the Région Wallonne for support in the frame of the: NANOCELL program. CERM is also indebted to the "Belgian Science Policy" for financial support in the frame of the "Interuniversity Attraction Poles Programme (PAI V/03)".

\section{References}

[1] P. Jannasch, Recent developments in high-temperature proton conducting polymer electrolyte membranes, Curr. Opin. Colloid Interf. Sci. 8 (2003) 96.

[2] F. Lufrano, I. Gatto, P. Staiti, V. Antonucci, E. Passalacqua, Sulfonated polysulfone ionomer membranes for fuel cells, Solid-State Ionics 145 (2001) 47

[3] J. Benavente, J.M. García, R. Riley, A.E. Lozano, J. de Abajo, Sulfonated poly(ether ether sulfones): characterization and study of dielectrical properties by impedance spectroscopy, J. Membr. Sci. 175 (2000) 43.

[4] L. Li, J. Zhang, Y. Wang, Sulfonated poly(ether ether ketone) membranes for direct methanol fuel cell, J. Membr. Sci. 226 (2003) 159.

[5] S. Kaliaguine, S.D. Mikhailenko, K.P. Wang, P. Xing, G. Robertson, M. Guiver, Properties of SPEEK based PEMs for fuel cell application, Catal. Today 82 (2003) 213.

[6] K. Ramya, K.S. Dhathathreyan, Poly(phenylene oxide)-based polymer electrolyte membranes for fuel cell applications, J. Appl. Polym. Sci. 88 (2003) 307.

[7] P. Staiti, M. Minutoli, S. Hocevar, Membranes based on phosphotungstic acid and polybenzimidazole for fuel cell application, J.Power Sources 90 (2000) 231

[8] B.S. Pivovar, Y. Wang, E.L. Cussler, Pervaporation membranes in direct methanol fuel cells, J. Membr. Sci. 154 (1999) 155.

[9] N. Miyake, J.S. Wainright, R.F. Savinell, Evaluation of a sol-gel derived Nafion/silica hybrid membrane for proton electrolyte membrane fuel cell applications. I. Proton conductivity and water content, J. Electrochem. Soc. 148 (2001) 898

[10] P. Staiti, A.S. Aricò, V. Baglio, F. Lufrano, E. Passalacqua, V. Antonucci, Hybrid Nafion-silica membranes doped with heteropolyacids for application in direct methanol fuel cells, Solid-State Ionics 145 (2001) 101

[11] B. Tazi, O. Savadogo, Parameters of PEM fuel-cells based on new membranes fabricated from Nafion ${ }^{\circledR}$, silicotungstic acid and thiophene, Electrochim. Acta 45 (2000) 4329.

[12] B. Bonnet, D.J. Jones, J. Roziere, L. Tchicaya, G. Alberti, M. Casciola, L. Massinelli, B. Bauer, A. Peraio, E. Ramunni, Hybrid organicinorganic membranes for a medium temperature fuel cell, J. New Mater. Electrochem. Syst. 3 (2000) 87.

[13] R.K. Bharadwaj, Modeling the barrier properties of polymer-layered silicate nanocomposites, Macromolecules 34 (2001) 9189

[14] J.M. Thomassin, C. Pagnoulle, D. Bizzarri, G. Caldarella, A. Germain, R. Jerome, Nafion-layered silicate nanocomposite membrane, ePolymer 018 (2004).

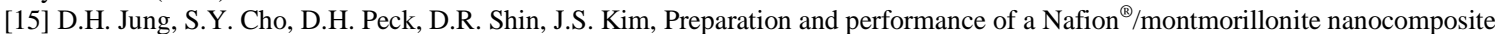
membrane for direct methanol fuel cell, J. Power Sources 118 (2003) 205.

[16] K.E. Strawhecker, E. Manias, Structure and properties of poly(vinyl alcohol)/ $\mathrm{Na}^{+}$montmorillonite nanocomposites, Chem. Mater. 12 (2000) 2943.

[17] N. Ogata, S. Kawakage, T. Ogihara, Poly(vinyl alcohol)-clay and poly(ethylene oxide)-clay blends prepared using water as solvent, J. Appl. Polym. Sci. 66 (1997) 573.

[18] M.A. Vargas, R.A. Vargas, B.E. Mellander, New proton conducting membranes based on PVAL/ $\mathrm{H}_{3} \mathrm{PO}_{2} / \mathrm{H}_{2} \mathrm{O}$, Electrochim. Acta 44 (1999) 4227.

[19] L. Li, L. Xu, Y. Wang, Novel proton conducting composite membranes for direct methanol fuel cell, Mater. Lett. 57 (2003) 1406.

[20] Z.G. Shao, X. Wang, I.M. Hsing, Composite Nafion/polyvinyl alcohol membranes for the direct methanol fuel cell, J. Membr. Sci. 210 (2002) 147.

[21] J. Kim, B. Kim, B. Jung, Proton conductivities and methanol permeabilities of membranes made from partially sulfonated polystyreneblock-poly(ethylene-ran-butylene)-block-polystyrene copolymers, J. Membr. Sci. 207 (2002) 129.

[22] V. Tricoli, N. Carretta, M. Bartolozzi, A comparative investigation of proton and methanol transport in fluorinated ionomeric membranes, J. Electrochem. Soc. 147 (2000) 1286. 